\title{
Comentarios sobre la constitucionalidad y legalidad de la reciente creación del Sistema de Seguridad Energética en Hidrocarburos y el Fondo de Inclusión Social Energético
}

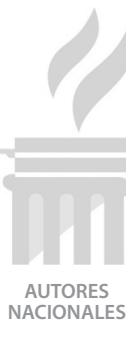

Fernando Tello Puerta

Abogado por la Universidad de Lima. Máster en Administración de Negocios por la Universidad de Lima y la Universidad Autónoma de Madrid.

SUMARIO: 


\section{INTRODUCCIÓN}

Como podrán recordar los lectores del presente ensayo, hace no mucho tiempo durante el mes de febrero de 2011 en medio de una intensa campaña política y a solo un par meses de las elecciones presidenciales, cierto candidato (ahora Jefe de Gobierno) asumió, en recordada asamblea celebrada en el mercado de San Antonio del Distrito de San Martín de Porres, el compromiso de reducir el precio del gas para consumo doméstico a un monto que equivaldría a menos del $50 \%$ del precio actual.

A poco más de un año del mencionado evento, se observa que el gobierno ha comenzado las labores de ejecución de la promesa planteada, promulgando con fecha 13 de abril de 2012 en el Diario Oficial El Peruano, la Ley 29852, Ley que crea el Sistema de Seguridad Energética en Hidrocarburos y el Fondo de Inclusión Social Energético.

De acuerdo con la norma citada, el Sistema de Seguridad Energética en Hidrocarburos, ha sido creado con la finalidad de dotar de infraestructura para brindar seguridad al sistema energético y estará constituido por redes de ductos e instalaciones de almacenamiento, que serán utilizadas para asegurar el abastecimiento de combustible del país.

Dicho sistema será financiado por disposición de la propia norma de su creación mediante cargos tarifarios aplicables sobre la infraestructura de la red nacional de ductos de transporte de los productos líquidos derivados de los hidrocarburos y líquidos del gas natural, cargos cuya determinación se efectuará por la vía reglamentaria mediante norma que deberá emitir el Ministerio de Energía y Minas.

De otro lado, el referido Fondo de Inclusión Social Energético (FISE), el cual estará destinado (i) a la masificación del uso del gas natural en sectores vulnerables, (ii) a la compensación para el desarrollo de nuevos suministros en la frontera energética, focalizándose en las poblaciones más vulnerables, y; (iii) a la compensación social y promoción para el acceso al GLP de los sectores vulnerables urbanos y rurales.
Dicho fondo se constituirá con los diferentes cargos que la norma de su creación ha establecido que deberán aplicarse sobre diversas actividades del sector energético (Hidrocarburos y Eléctrico).

En el marco de lo expuesto, es propósito del presente documento, analizar la naturaleza (tributaria o no) de los cargos que se efectuarán para la financiación del Sistema de Seguridad Energética y del Fondo de Integración Social Energético.

\section{A continuación, nuestros comentarios.}

\section{CONCEPTO Y CLASIFICACIÓN DE LOS TRIBUTOS}

De acuerdo con lo expresado por Hector Belisario Villegas en su "Curso de Finanzas, Derecho Financiero y Tributario", una observación de las necesidades humanas en general demuestra que éstas son múltiples y aumentan en razón directa con el nivel de civilización que alcanza una sociedad.

Algunas de dichas necesidades son de satisfacción indispensable para la vida normal del hombre, pudiendo ser inmateriales (como las intelectuales, religiosas, morales) o materiales (alimentación vestido, vivienda, entre otras).

El señalado autor continúa indicando que ambos grupos de necesidades se identifican con la propia existencia de las personas y son innatas a cada individuo aisladamente considerado de manera tal que su satisfacción puede ser indistintamente efectuada por el propio sujeto o por el Estado en algunos casos.

No obstante lo expuesto la experiencia nos enseña que existe otro tipo de necesidades que trascienden al ser humano individualmente considerado, las mismas que surgen de la vida en sociedad de los seres humanos individuales. A decir del autor, estas necesidades están relacionadas, entre otras, con la seguridad, el transporte, las comunicaciones y el aprendizaje.

Pues bien, cuando los individuos resuelven integrarse en una colectividad surgen ideales comunes que primariamente, son defenderse 
recíprocamente, crear normas de convivencia y velar por su acatamiento, así como buscar el medio de resolver controversias y castigar las infracciones con el mayor grado de justicia. Estos ideales dan lugar a las necesidades públicas.

Considerando que estas necesidades son de imposible satisfacción mediante esfuerzos aislados, el ser humano asociado tiende a buscar a alguien que aúne los esfuerzos particulares. En la actualidad dicho rol ha sido asumido por los distintos gobiernos de los Estados Nacionales. Dichos gobiernos son los encargados de proporcionar servicios públicos destinados a la satisfacción de las necesidades públicas.

A estas alturas, resultará obvio para el lector que los servicios públicos deben ser financiados de alguna forma. Tradicionalmente el financiamiento requerido por los gobiernos para la realización de sus fines se obtiene básicamente, de los tributos y/o de la propia actividad empresarial del Estado. El deseo de contribuir con el sostenimiento del Estado es lo que se conoce como cultura tributaria.

Los tributos corresponden entonces a prestaciones dinerarias o en especie que el Estado exige en el ejercicio de su ius imperium, con la finalidad de cubrir aquellos gastos generados por la demanda de satisfacción de las necesidades públicas. Mediante los tributos, los integrantes del Estado contribuyen al sostenimiento del gobierno en proporción a su respectiva capacidad contributiva.

Definido el concepto de tributo, resulta necesario ahora establecer una clasificación de los mismos. De acuerdo con Geraldo Ataliba', en cuanto a su clasificación los tributos pueden considerarse como vinculados o no vinculados.

Los tributos vinculados son aquellos cuyo hecho generador está estructurado de tal manera que integran una actividad o cargo del Estado que de alguna manera afecta la interesado o repercute en su patrimonio. Estos a su vez se dividen en tasas y contribuciones dependiendo de si la actividad estatal genera un beneficio directo e individualizado o indirecto para los contribuyentes.

Por otro lado, en los tributos no vinculados no existe conexión del obligado con una actividad estatal específica que lo beneficie. La obligación en este caso, nacerá en virtud de un hecho que según la valoración del legislador revela capacidad de contribuir al sostenimiento del Estado.

La clasificación descrita ha sido recogida por la legislación peruana en la Norma II del Tïtulo Preliminar del Código Tributario, cuyo Texto Único Ordenado ha sido aprobado por Decreto Supremo 155-99-EF (Código Tributario) según la cual el término genérico tributo comprende:

a) A los Impuestos, definidos como tributos cuyo cumplimiento no origina una contraprestación directa en favor del contribuyente por parte del Estado.

b) A las contribuciones, definidas como tributos cuya obligación tiene como hecho generador beneficios derivados de la realización de obras públicas o de actividades estatales.

c) A las tasas, definidas como tributos cuya obligación tiene como hecho generador la prestación efectiva por el Estado de un servicio público individualizado en el contribuyente.

Las Tasas, entre otras, pueden ser:

- Arbitrios: son tasas que se pagan por la prestación o mantenimiento de un servicio público.

- Derechos: son tasas que se pagan por la prestación de un servicio administrativo público o el uso o aprovechamiento de bienes públicos.

- Licencias: son tasas que gravan la obtención de autorizaciones específicas

1. ATALIBA, Geraldo. Hipótesis de Incidencia Tributaria. p. 133 y ss. 
para la realización de actividades de provecho particular sujetas a control o fiscalización.

\section{LA POTESTAD TRIBUTARIA Y EL PRINCIPIO DE LEGALIDAD}

Habiendo definido cuál es el concepto de tributo y como éstos se clasifican de acuerdo con la legislación peruana, es importante ahora definir quienes son aquellos sujetos jurídicamente capaces de crear tributos. Nótese que si el estado tuviese la capacidad irrestricta de crear obligaciones tributarias podría caer en supuestos de abuso de su ius imperium, los cuales deben ser evitados.

Sobre el particular, debemos indicar que en tanto prestador de servicios públicos, es el Estado el que resulta siendo titular de la potestad tributaria. Esto es, de la capacidad para crear, modificar y suprimir unilateralmente tributos. No obstante, dicha potestad tiene determinados límites entre los cuales se encuentran el principio de legalidad y la capacidad contributiva de los contribuyentes.

El principio de legalidad descrito, es uno de los pilares fundamentales del derecho tributario y puede ser sintetizado en la expresión: "no hay tributo sin ley que lo establezca".

Este principio que todo tributo sea sancionado por una Ley, entendida ésta como la disposición que emana del órgano constitucional que tiene la potestad legislativa conforme a los procedimientos establecidos en la Constitución para la sanción de Leyes y halla su fundamento su fundamento en la necesidad de proteger el derecho de propiedad de los contribuyentes de aquello actos de exacción ilegítima a que pudieran estar inclinados los miembros de los órganos ejecutivos del Estado, en la búsqueda de fondos para la financiación de las actividades del mismo.

El Perú no es ajeno a la doctrina descrita. En efecto de acuerdo con el artículo 74 de la Constitución Política de 1993, en nuestro país los tributos se crean, modifican o derogan, o se establece una exoneración, exclusivamente por ley o decreto legislativo en caso de delegación de facultades, salvo los aranceles y tasas, los cuales se regulan mediante decreto supremo.

De igual manera, los Gobiernos Regionales y los Gobiernos Locales pueden crear, modificar y suprimir contribuciones y tasas, o exonerar de éstas, dentro de su jurisdicción, con los límites que señala la ley. El Estado, al ejercer la potestad tributaria, debe respetar los principios de reserva de la ley, y los de igualdad y respeto de los derechos fundamentales de la persona.

El propio artículo mencionado señala que no surten efecto las normas tributarias dictadas en violación de los preceptos descritos.

De manera complementaria a lo expuesto, la Norma IV del Título Preliminar del mencionado Código Tributario establece que solo por Ley o Decreto Legislativo en caso de delegación de facultades, se puede:

- Crear, modificar y suprimir tributos, señalar el hecho generador de la obligación tributaria, la base para su cálculo y la alícuota, el acreedor tributario, el deudor tributario y el agente de retención o percepción.

- Conceder exoneraciones y otros beneficios tributarios.

- Normar los procedimientos jurisdiccionales, así como los administrativos en cuanto a derechos o garantías del deudor tributario.

Definir las infracciones y establecer sanciones.

- Establecer privilegios, preferencias y garantías para la deuda tributaria.

- Normar formas de extinción de la obligación tributaria distintas a las establecidas en el propio Código Tributario.

La norma citada añade que los Gobiernos Locales, mediante Ordenanza, pueden crear, modificar y suprimir sus contribuciones, arbitrios, derechos y licencias o exonerar de ellos, 
dentro de su jurisdicción y con los límites que señala la Ley. ${ }^{2}$

De igual manera, mediante Decreto Supremo refrendado por el Ministro de Economía y Finanzas se regula las tarifas arancelarias.

Por otro lado, por Decreto Supremo refrendado por el Ministro del Sector competente y el Ministro de Economía y Finanzas, se fija la cuantía de las tasas.

\section{EL SISTEMA DE SEGURIDAD ENERGÉTICA EN HIDROCARBUROS}

De acuerdo con los antecedentes planteados, el Sistema de Seguridad Energética en Hidrocarburos, ha sido creado con la finalidad de dotar de infraestructura para brindar seguridad al sistema energético y estará constituido por redes de ductos e instalaciones de almacenamiento, que serán utilizadas para asegurar el abastecimiento de combustible del país.

Dicho sistema será financiado mediante cargos tarifarios aplicables sobre la infraestructura de la red nacional de ductos de transporte de los productos líquidos derivados de los hidrocarburos y líquidos del gas natural, cargos cuya determinación se efectuará por la vía reglamentaria mediante norma que deberá emitir el Ministerio de Energía y Minas.

Sobre el particular debemos indicar que conforme a lo expuesto, no cabe duda de que la naturaleza de los cargos que se efectúen sobre la utilización de la estructura de transporte de hidrocarburos y gas natural para el financiamiento del Sistema de Seguridad Energética en Hidrocarburos corresponderá a la de un tributo.

Añadimos que en el caso materia de análisis, dicho tributo deberá ser clasificado a su vez bajo el concepto de contribución recogido por la Norma II del Código Tributario. Ello en la medida que corresponde a la realización de una obra pública que generará beneficios no individualizados en los contribuyentes.

Ahora bien, atendiendo a la naturaleza tributaria de la institución, se hace necesario analizar si la misma cumple con los requisitos de legalidad mínimos establecidos por la Constitución y el Código Tributario comentados de manera precedente,

De esta manera concluimos que desde el punto de vista tributario, la Ley 29852 materia de comentario debe, respecto de los cargos para financiar el Sistema de Seguridad Energética en Hidrocarburos:

- Expresar cual será el hecho generador del cargo.

- Expresar quienes serán el acreedor y el deudor de las obligaciones generadas.

- Establecer el momento en que dichos cargos deberán ser abonados al acreedor.

- Establecer la base de cálculo del cargo y la forma de determinación del mismo.

- Establecer la jurisdicción tributaria aplicable.

No obstante ello, la propia Ley 29852 ha establecido que la determinación de la base de cálculo y la forma de determinación de los cargos para el financiamiento de Sistema de Seguridad Energética en Hidrocarburos será determinada por el Ministerio de Energía y Minas.

Se observan entonces claros problemas de constitucionalidad y legalidad de la norma materia de comentario los cuales sin duda afectarán la eficacia de la misma y generarán retrasos en la implementación del Sistema.

2. Ello considerando que a diferencia de los impuestos y las contribuciones, las tasas constituyen la retribución por un servicio público individualizado en un determinado contribuyente lo cual implica el cálculo del costo del servicio prestado. Esto no ocurre en el caso de las contribuciones o de los impuestos. 


\section{EL FONDO DE INCLUSIÓN SOCIAL ENERGÉTICO}

Como se indica en la parte introductoria del presente ensayo, la Ley 29852 bajo comentario, ha creado adicionalmente el Fondo de Inclusión Social Energético (FISE), el cual estará destinado a:

(i) La masificación del uso del gas natural en sectores vulnerables,

(ii) La compensación para el desarrollo de nuevos suministros en la frontera energética, focalizándose en las poblaciones más vulnerables, y;

(iii) La compensación social y promoción para el acceso al GLP de los sectores vulnerables urbanos y rurales.

El artículo 4 de la norma bajo comentario establece que el FISE se financiará a través de:

- Recargos en la facturación mensual para los usuarios libres de electricidad de los sistemas interconectados definidos como tales por el Reglamento de la Ley de Concesiones Eléctricas Decreto Ley 25844, a través de un cargo equivalente en energía aplicable en las tarifas de transmisión eléctrica. Dicho cargo tarifario será equivalente al recargo en la facturación dispuesto por la Ley de Creación del Fondo de Compensación Social Eléctrica, Ley 27510 y normas complementarias y conexas.

- Recargo al transporte por ductos de los productos líquidos derivados de hidrocarburos y líquidos de gas natural, equivalente a US\$ 1.00 por barril a los mencionados productos. El recargo se aplicará en cada venta primaria que efectúen los productores e importadores definidos como tales en el Glosario Siglas y Abreviaturas del Subsector Hidrocarburos, aprobado por Decreto Supremo 032-2002-EM y será trasladado en los precios de los hidrocarburos líquidos.

- Recargo equivalente a US\$ 0.055 por MPC (Miles de Pies Cúbicos) en la facturación mensual de los cargos tarifarios de los usuarios de servicio de transporte de gas natural por ductos, definidos como tales por el Reglamento de Transporte de Hidrocarburos por Ductos, aprobado por Decreto Supremo 081-2007-EM.

De acuerdo con el análisis que hemos efectuado respecto de las normas que regulan el mencionado fondo, concluimos que en atención a los lineamientos descritos en el punto II. precedente, los cargos para su financiamiento tendrán naturaleza tributaria debiendo clasificarse los mismos como un Impuesto. Ello en la medida que los cargos a ser efectuados no corresponden en modo alguno, a la realización de una actividad por parte del Estado.

Siendo ese el caso, a continuación trataremos de determinar si las normas que crean el Fondo de Inclusión Social Energético son acordes con el principio de reserva de la Ley en materia tributaria contenido en el artículo 74 de la Constitución Política del Perú y con la Norma II del Código Tributario antes referidas.

De una lectura de la norma bajo comentario podemos afirmar:

- Que el hecho gravado será el uso del sistema interconectado de transmisión eléctrica así como la operación y uso del sistema de transporte de hidrocarburos y gas natural.

- Que el acreedor de los aportes al fondo es el Estado y los deudores serán los usuarios libres de los sistemas interconectados de transmisión eléctrica, los transportistas de hidrocarburos y gas natural y los usuarios del servicio de transporte de hidrocarburos y gas natural.

- Que el aspecto espacial estará constituido por el territorio nacional.

Sin perjuicio de ello, la norma bajo comentario falla al establecer los aspectos temporal y cuantitativo de los aportes al Fondo de Inclusión Social Energético. En efecto, la norma:

- $\quad$ Si bien establece que los aportes se harán efectivos mediante recargos en la factura- 
ción a los usuarios del sistema interconectado de transmisión eléctrica y operadores y usuarios del sistema de transporte de hidrocarburos y gas natural no señala cual será el momento en que deberán abonarse los fondos al acreedor tributario.

- De igual manera, en el caso de los usuarios del sistema interconectado de transmisión eléctrica, la norma remite la determinación del aporte el fondo a las normas que regulan el Fondo de Compensación Eléctrica, las mismas que a su vez remiten la determinación del aporte a éste último al Osinergmin.

- En este caso, remitir la determinación de la base de cálculo y el importe de un tributo a un órgano administrativo, constituye una clara violación del principio de reserva de la Ley establecido por las normas glosadas a lo largo del presente ensayo.

Siendo ese el caso, se concluye que las normas de creación del Fondo de Inclusión Social Eléctrico también manifiestan rasgos de inconstitucionalidad e ilegalidad en su creación.

\section{CONCLUSIONES}

- Como se ha indicado en los párrafos anteriores, los aportes al Sistema de Seguridad Energética en Hidrocarburos y al Fondo de Inclusión Social Energética que deban efectuar los sujetos establecidos por las normas citadas constituyen tributos y por tanto deben someterse al régimen tributario nacional, esto es, cumplir con los princi- pios y límites constitucionales vigentes de la tributación, en especial el principio de legalidad.

- La Ley 29852 omite en el caso del Sistema de Seguridad Energética en Hidrocarburos la determinación de la base de cálculoy el importe de la contribución al sistema, delegándola al Ministerio de Energía y Minas en abierta violación a los principios que rigen la creación de tributos en el Perú. El Ministerio de Energía y Minas no puede en efecto, ocuparse de la regulación de parte de la determinación de un tributo que por disposición constitucional corresponde a normas de rango legal.

- Igual defecto ocurre en el caso del aporte al Fondo de Inclusión Social Energético de usuarios del sistema interconectado de transmisión eléctrica. En este caso, la norma remite la determinación del aporte el fondo a las normas que regulan el Fondo de Compensación Eléctrica, las que a su vez remiten la determinación del aporte a éste último al Osinergmin, organismo que no tiene capacidad jurídica para la regulación de aspectos que corresponde sean determinados por normas de rango legal.

Atendiendo a que la finalidad de las normas materia de comentario es la de incentivar el acceso de las poblaciones menos favorecidas a recursos básicos como el gas natural para consumo doméstico esperamos que en breve, los defectos normativos en la Ley 29852 sean corregidos en breve, con la finalidad de no comprometer su eficacia. 